$\begin{array}{lllllllllllllll}\text { A C T A } & \text { C H E M I A } & \text { S C A N D I N A V I C A } & 23 & (1969) & 37-46\end{array}$

\title{
On the Infrared Spectra of Some Mixed Thiocyanato Complexes
}

\author{
RAGNAR LARSSON and ATIS MIEZIS \\ Divison of Inorganic Chemistry, Chemical Center, University of Lund, Box 740, \\ S-220 07 Lund 7, Sweden
}

\begin{abstract}
A model of intensity behaviour of the stretching vibrations of the thiocyanate group in thiocyanato complexes is discussed. As an example infrared spectra in the $\mathbf{C}-\mathbf{N}$ absorption region have been recorded for some mixed palladium(II) thiocyanato complexes both in solution and in solid state. It has been concluded that the integrated absorption of the $\mathrm{C}-\mathrm{N}$ band of the complexes as compared to that of the "free" thiocyanate ion is a good criterion on the type of coordination (M-SCN or M-NCS bonding), but that only values obtained in the same solvent or dispersion medium are fully comparable.
\end{abstract}

$\mathrm{T}^{\mathrm{s}}$ he question of bonding in metal ion-thiocyanato complexes and the relationship of this bonding to the infrared spectrum of the thiocyanato ligand has been the object of many recent investigations and discussions. ${ }^{1-9}$ Mostly, investigators have used the frequency shifts of the $\mathrm{C}-\mathrm{N}$ and $\mathrm{C}-\mathrm{S}$ stretching vibrations as a diagnostic tool for differentiating between M-SCN and M-NCS bonding.

The most reliable criterion on bonding from frequency shifts now appears to be that related to the bending vibration $\left(v_{2}\right)^{4,5} \mathrm{It}$ is found that M-SCN complexes absorb in the range $410-440 \mathrm{~cm}^{-1}$ and the M-NCS ones in the range $450-490 \mathrm{~cm}^{-1}$. Unfortunately, it is not possible to observe this absorption in aqueous solutions due to the strong absorption of water, nor with any great success in other solvents because of the low intensity of the $\nu_{2}$ absorption. Another approach to differentiating between linkage isomers is that of intensity measurements of the $\mathrm{C}-\mathrm{N}$ stretching absorption. This method is especially important for solutions. In an earlier work ${ }^{1}$ from this laboratory it was shown that two classes of complexes could easily be distinguished in this way. The first class consisted of complexes that showed an increase in the $\mathrm{C}-\mathrm{N}$ stretching intensity compared with the free $\mathrm{SCN}^{-}$ion, whilst the other class was characterized by a corresponding decrease. The first mentioned class was attributed to complexes of the M-NCS type; the second one to complexes of the type M-SCN. This classification has since been verified and amplified.?

Acta Chem. Scand. 23 (1969) No. 1 


\section{MODEL OF THE INTENSITY AND FREQUENCY BEHAVIOUR}

The increase and decrease, respectively, of the intensity in question could be rationalized from a simple valence bond picture. Thus the ligand is considered as the vibrating unit, with no regard being taken to the presence of the metal ion, nor to the eventual appearance of more than one $\mathrm{C}-\mathrm{N}$ vibration in complexes containing more than one $\mathrm{SCN}^{-}$ligand, i.e. the $\mathrm{C}-\mathrm{N}$ vibration modes expected to appear for multithiocyanato complexes of low symmetry are regarded as accidentally degenerate in solutions. The validity of this assumption is amplified by a recent study on inert $\operatorname{Cr}(\mathrm{NCS})_{4} \mathrm{~L}_{2}$ complexes by Bennett, Clark and Goodwin. ${ }^{8}$ As the authors do not give any description of the band form or halfwidth, it is of course not possible to exclude a small splitting. If the asymmetric form of the $\mathrm{C}-\mathrm{N}$ band observed for the tetrahedral $\mathrm{Co}\left[\mathrm{P}\left(\mathrm{C}_{6} \mathrm{H}_{5}\right)_{3}\right]_{2}(\mathrm{NCS})_{2}$ and $\mathrm{Zn}\left[\mathrm{P}\left(\mathrm{C}_{2} \mathrm{H}_{5}\right)_{3}\right]_{2}(\mathrm{NCS})_{2}{ }^{7}$ is caused by the two infrared active vibration modes that are principally to be expected, or if they are due to some solvolytic reaction creating different species is an interesting question that cannot be answered without a detailed analysis of the equilibria involved (cf. Cotton et al. p. 4158). ${ }^{10}$

Thus regardless of the $\mathrm{M}-\mathrm{NC}$ angle or the $\mathrm{M}-\mathrm{SC}$ angle the thiocyanate group could be represented by the canonical structures given by Jones. ${ }^{11}$

$$
-\mathrm{S}-\mathrm{C} \equiv \mathrm{N} \text {, }
$$

(a)

$$
\mathrm{S}=\mathrm{C}=\mathrm{N}^{-} \quad \text { and }
$$

(b)

$$
+\mathrm{S} \equiv \mathrm{C}-\mathrm{N}^{2-}
$$

It was then argued ${ }^{1}$ that a complex of the type $M \leftarrow$ NCS should benefit from an increase of negative charge on the $\mathrm{N}$-atom of the thiocyanate ion thus rehybridizing so that more of the forms (c) and (b) were present whereas a complex of the type $\mathrm{M} \leftarrow \mathrm{SCN}$ would benefit from a corresponding rehybridizing resulting in a larger proportion of form (a).

Hence from a fixed charge model the intensity of the $\mathrm{C}-\mathrm{N}$ band of an M-NCS complex should be higher than that of the free $\mathrm{SCN}^{-}$ion and the frequency should be lower as the bond order is somewhat lower. It must be remembered that the dominant resonance structure evidently is always the (a) form since the $\mathrm{C}-\mathrm{N}$ stretching frequency is always in the range of that of a $\mathbf{C} \equiv \mathrm{N}$ bond. Conversely, M-SCN complexes should have a lower $\mathrm{C}-\mathrm{N}$ stretching intensity and a higher frequency of the same band. This argument also predicts, as has been found, that the $\mathrm{C}-\mathrm{S}$ stretching frequency of the M-NCS complexes must be higher than that of M-SCN complexes. The corresponding prediction regarding the intensities, i.e. lower $\mathrm{C}-\mathrm{S}$ stretching intensity of the M-NCS complexes and a higher one for the M-SCN complexes compared with that of the free ligand, seems not to have been exemplified although it is implicit in the remark by Pecile, ${ }^{7}$ viz. the $\mathrm{C}-\mathrm{S}$ stretching band in $\mathrm{Co}\left[\mathrm{P}\left(\mathrm{C}_{6} \mathrm{H}_{5}\right)_{3}\right]_{2}(\mathrm{NCS})_{2}$ has a very low intensity.

So far this simple approach yields results of obvious, pragmatic value. Some difficulties, however, remain to be settled. The main problem connected with the model proposed is the shift of the $\mathrm{C}-\mathrm{N}$ stretching band towards higher frequencies found in most M-NCS complexes. It is this shift that has made the $\mathrm{C}-\mathrm{N}$ stretching frequency a bad criterion for distinguishing between linkage isomers. It has previously been proposed $^{1}$ that this effect should 
result from a superposition of the decrease expected from the model and an increase caused by mere mechanical squeezing of the $\mathrm{C}-\mathrm{N}$ group between the positive charge on the metal and the negative one situated mainly on the sulphur atom. It is pleasing to note that a much more elaborate treatment has been given by Porai-Koshits and workers. ${ }^{12}$ They show that even if the force constants $k_{\mathrm{NC}}$ and $k_{\mathrm{cs}}$ of the thiocyanate ion are regarded as constant (i.e. the degree of hybridization is unchanged) any metal ion-nitrogen interaction, even a "pure" electrostatic one, gives rise to an increase in the $\mathrm{C}-\mathrm{N}$ stretching frequency. Moreover, this increase is almost linearly related to $k_{\mathrm{MN}}$, the metal-nitrogen stretching force constant. From this point of view, it is interesting that the frequency shift observed experimentally was found to be proportional to $\log k_{1}{ }_{1}^{13}$ where $k_{1}$ is the stability constant of the first thiocyanato complex. It then seems plausible, that $k_{\mathrm{MN}}$ is proportional to $\log k_{1}$ or rather to the enthalpy of formation of the complex. Although there is no strict theoretical foundation for a linear relation between the stretching force constant of a bond $A-B$ and the bond energy, some examples appear for molecules of similar types where such a relationship does hold, e.g. the hydrogen halides ( $c f$. Ref. 14, p. 9-10). Therefore the recent findings of Nancollas ${ }^{15}$ yielding a positive enthalpy of formation of the $\mathrm{ZnNCS}^{+}$complex but negative values for all other MNCS $^{+}$complexes are somewhat surprising.

The testing of the proposed intensity relations seems to be an undertaking worth while. Especially disturbing is the effect in the case of the thiocyanato complexes of the first-row transition metals in their-two-valent state. For these complexes in aqueous solution Fronæus and Larsson ${ }^{1}$ found within experimental errors a constancy of the $\mathrm{C}-\mathrm{N}$ stretching intensity and moreover this intensity was found to be equal to that of the free ligand. From the arguments above a very small charge transfer from the nitrogen to the metal should be expected in these complexes. Examples of extreme covalency in M-NCS complexes are difficult to find. However, one notes that the tetrahedral species $\mathrm{Co}(\mathrm{NCS})_{4}{ }^{2-1}$ and $\mathrm{Zn}(\mathrm{NCS})_{4}{ }^{2-16}$ give an increase of the $\mathrm{C}-\mathrm{N}$ stretching intensity compared with the free thiocyanate ion as well as a much less pronounced increase of frequency than the octahedral complexes $\mathrm{Co}\left(\mathrm{OH}_{2}\right)_{5} \mathrm{NCS}^{+}$ and $\mathrm{Zn}\left(\mathrm{OH}_{2}\right)_{5} \mathrm{NCS}^{+}$. This is obviously related to the much greater covalency in tetrahedral complexes, reflected by the greater nephelauxetic effect $(c f$., e.g., the difference in the Racah parameter $\mathrm{B}$ of $\mathrm{Co}\left(\mathrm{OH}_{2}\right)_{6}{ }^{2+}$ and $\mathrm{CoCl}_{4}{ }^{2-}$, Ref. 17, p. 240).

For systems where the central atom - thiocyanate bonding is of a much more covalent type, as e.g., in the phosphorus compounds $\mathrm{P}(\mathrm{NCS})_{3}$ and $\mathrm{OP}(\mathrm{NCS})_{3}$ one should expect that the main assumption of our model - the almost complete independence of the $\mathrm{SCN}^{-}$group from the rest of the molecule - will no longer hold. Furthermore, the more pronounced delocalisation of binding electrons will cause a deviation from the simple fixed-charge model for the intensity. This is strikingly illustrated in the spectra recorded by Oba, Watari and Aida. ${ }^{18}$ The frequencies of the $\mathrm{C}-\mathrm{N}$ and $\mathrm{C}-\mathrm{S}$ stretching vibrations of the NCS $^{-}$group, had the vibration modes been degenerated, should obviously have been situated somewhere below $2000 \mathrm{~cm}^{-1}$ and well above $1000 \mathrm{~cm}^{-1}$, respectively. This is in accordance with the proposed scheme for strongly covalent bonding, but the intensities do not follow the rules 
suggested above. As expected from the model the $\mathrm{C}-\mathrm{N}$ band has a very high intensity $-\varepsilon \cdot \Delta v_{1 / 2}=2 \times 10^{6} \mathrm{M}^{-1} \mathrm{~cm}^{-2}$, estimated from the reported spectrum - but also the $\mathrm{C}-\mathrm{S}$ band has an intensity that is not more than about ten times smaller than the $\mathrm{C}-\mathrm{N}$ stretching intensity. The model would predict a much smaller value, i.e. a value below that of the free thiocyanate ion which has been found to be of the order $10^{3} \mathrm{M}^{-1} \mathrm{~cm}^{-2}$. Thus it is quite evident that the simple model breaks down in cases like this.

It emerges from this example that the intensity of the $\mathrm{C}-\mathrm{S}$ stretching vibration is indeed a most useful and important object for the continued elucidation of the degree of interaction between metal and ligand in thiocyanato complexes. As this part of the spectrum is difficult to observe for solutions, solid state observations may turn out to be the only ones possible.

\section{FURTHER EXAMINATIONS OF THE PROPOSED INTENSITY RULE}

In order to pave the way towards measurements of the $\mathrm{C}-\mathrm{S}$ band intensity - besides the legitimate interest of their own that such measurements may have - we have tried to make some measurements of the $\mathrm{C}-\mathrm{N}$ band intensity of a few complexes in the solid state. As examples some mixed palladium(II) thiocyanato complexes, namely $\mathrm{Pdpy}_{2}(\mathrm{SCN})_{2}, \mathrm{Pd}\left[\mathrm{P}\left(\mathrm{C}_{6} \mathrm{H}_{5}\right)_{3}\right]_{2}(\mathrm{NCS})_{2}$, and the linkage isomers $\mathrm{Pd}\left[\mathrm{As}\left(\mathrm{C}_{6} \mathrm{H}_{5}\right)_{3}\right]_{2}(\mathrm{NCS})_{2}$ and $\mathrm{Pd}\left[\mathrm{As}\left(\mathrm{C}_{6} \mathrm{H}_{5}\right)_{3}\right]_{2}(\mathrm{SCN})_{2}$ have been chosen. For all these complexes the type of linkage isomerism has been established by means of frequency observations.

To measure the intensity the integrated absorption, $A$, obtained by direct graphical integration of the absorption bands, was used. $A$ is defined as

$$
A=\frac{c d}{1} \int \ln \left(I_{0} / I_{\nu}\right) \mathrm{d} \nu
$$

where $c=$ concentration, $d=$ thickness of sample, $\nu=$ frequency, and $I=$ transmitted light.

In previous works ${ }^{1,9,19}$ the integrated absorption has not been determined explicitly but a more easily handled quantity has been used: the product $\varepsilon_{\max } \Delta \nu_{1 / 2}$, where $\varepsilon_{\max }$ is the molar absorptivity at the maximum of the absorption band and $\Delta v_{1 / 2}$ the half band width. This product is proportional to the integrated absorption. Assuming that the absorption band could be described by Lorenz functions and $\varepsilon_{\max }$ and $\Delta v_{1 / 2}$ were the true molar absorptivity and half-width, respectively, the integrated absorption would be

$$
A=(\pi / 2) \ln 10 \times \Delta v_{1 / 2} \times \varepsilon_{\max }=3.6 \times \Delta v_{1 / 2} \times \varepsilon_{\max }
$$

as

$$
\varepsilon_{\max }=\frac{1}{c d} \log \frac{I_{0}}{I_{\max }}
$$

In practice the deviation of the proportionality factor from the value 3.6 can be obtained from, e.g., Ramsay's tables. ${ }^{20}$

As the $\mathrm{C}-\mathrm{N}$ absorption bands of the examined thiocyanato complexes are rather symmetrical, and the same slit width has been used, one could 
assume the proportionality factor to be approximately the same for all samples. Thus $\varepsilon_{\max } \Delta \nu_{1 / 2}$ could be used instead of $A$ as a fairly good criterion on linkage isomerism of thiocyanato complexes.

\section{EXPERIMENTAL}

All spectra were run on a Perkin-Elmer Model 521 with a grating monochromator. The wave-number readings of the spectrophotometer were checked by recording spectra of carbon monoxide. The slit was determined by the slit program of the instrument and the setting of this corresponded to a mechanical slit opening in the actual range of frequencies of about $100 \mu$. The solid samples were examined in $\mathrm{KBr}$ disks whereas for the solutions matched NaCl-cells were used. The concentration of the solid sample was obtained by determination of the weight ratio between sample and $\mathrm{KBr}$ before the disk was pressed and by measurements of the volume of the disk afterwards.

\section{A. Measurements on $\operatorname{Pdpy}_{2}(\mathrm{SCN})_{2}$}

Preparation. Cf. Ref. 2. $\mathrm{PdCl}_{2}$ was dissolved in water, acidified with $\mathrm{HCl}$ and a solution of NaSCN in water was added. The precipitate of $\operatorname{Pd}(\mathrm{SCN})_{2}$ was dissolved again in an excess of NaSCN forming the complex $\mathrm{Pd}(\mathrm{SCN})_{4}{ }^{2-}$. The $\mathrm{pH}$ of this solution was adjusted to $c a .5$ with $\mathrm{NaOH}$ and then pyridine was added dropwise. The yellow product that appeared $\left(\mathrm{Pdpy}_{2}(\mathrm{SCN})_{2}\right)$ was isolated by filtration, washed with water, ethanol, and ether and dried in vacuo over $\mathrm{P}_{2} \mathrm{O}_{5}$.

Results. Pdpy ${ }_{2}(\mathrm{SCN})_{2}$ is rather insoluble in most inert solvents but it can be dissolved in pyridine. The recorded spectra of $\mathrm{Pdpy}_{2}(\mathrm{SCN})_{2}$ in pyridine showed three distinct absorption peaks: one large at 2116 and two smaller at 2085 and $2057 \mathrm{~cm}^{-1}$, respectively (Fig. 1). The last one seems to be the free thiocyanate peak and if so it is plausible that the peaks at 2116 and $2085 \mathrm{~cm}^{-1}$ are caused by the $\mathrm{C}-\mathrm{N}$ stretching vibration in $\mathrm{Pdpy}_{2}(\mathrm{SCN})_{2}$ and $\mathrm{Pdpy}_{3}(\mathrm{NCS})^{+}$, respectively, the latter being formed when the pyridine forces one of the SCN ${ }^{-}$groups out of its original place:

$$
\mathrm{Pdpy}_{2}(\mathrm{SCN})_{2}+\mathrm{py} \longrightarrow \mathrm{Pdpy}_{3}(\mathrm{NCS})^{+}+\mathrm{SCN}^{-}
$$

Under this assumption and using the molar absorptivity of $\mathrm{SCN}^{-}$in pyridine, known from earlier investigations ${ }^{0}$ to be $\varepsilon_{\mathrm{SCN}^{-}}=1.02 \times 10^{3} \mathrm{M}^{-1} \mathrm{~cm}^{-1}$, the amounts of $\operatorname{Pdpy}_{2}(\mathrm{SCN})_{2}$ and $\mathrm{Pdpy}_{3}(\mathrm{NCS})^{+}$could be calculated. As a test of the validity of the calculated values

Fig. 1. C-N stretching absorption bands of a $20.6 \mathrm{mM}$ solution of $\mathrm{Pdpy}_{2}(\mathrm{SCN})_{2}$ in pyridine. Cell thickness $0.207 \mathrm{~mm}$.

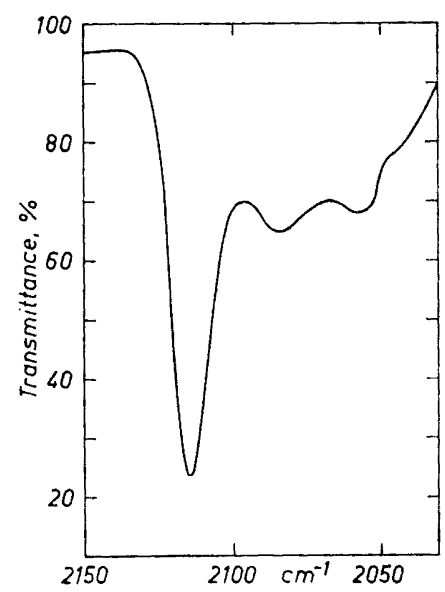

Acta Chem. Scand. 23 (1969) No. 1 

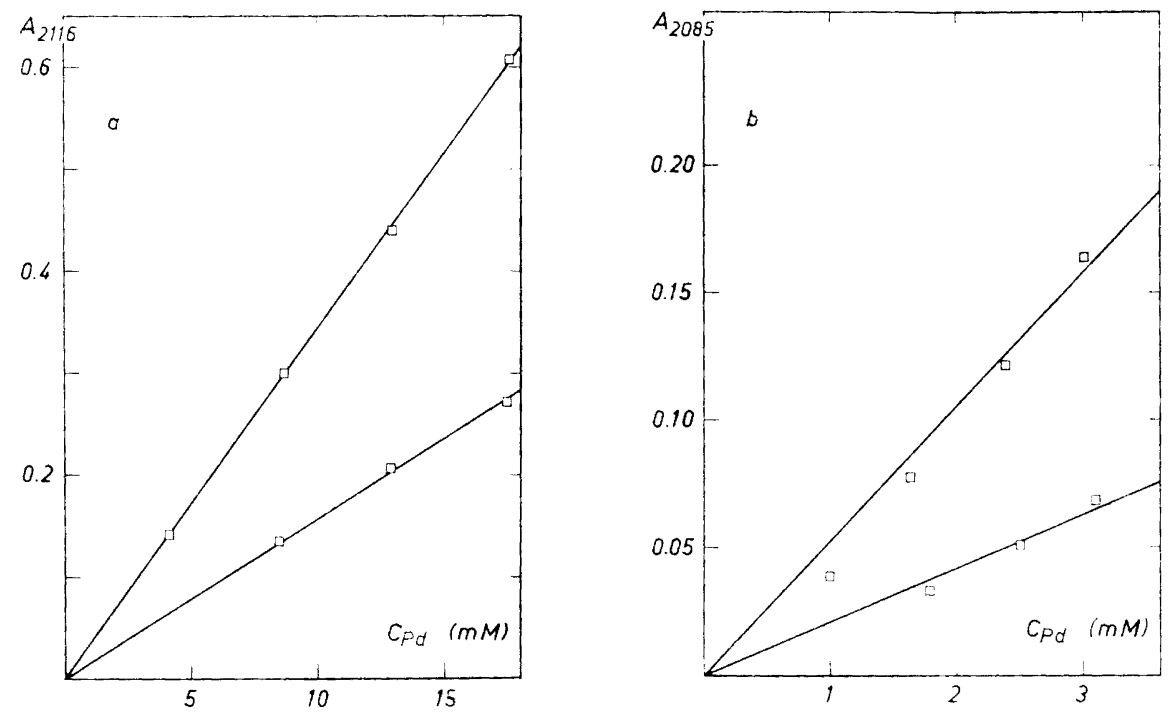

Fig. 2. The Beer-law plots of a) $\mathrm{Pdpy}_{2}(\mathrm{SCN})_{2}$ and b) $\mathrm{Pdpy}_{3}(\mathrm{NCS})^{+}$in pyridine solutions. The upper lines correspond to cell thicknesses of $0.473 \mathrm{~mm}$, the lower lines to $0.207 \mathrm{~mm}$.

Beer-law plots were made. See Figs. 2 and 3. There is no doubt that the thiocyanate ion is bonded to $\mathrm{Pd}$ via $\mathrm{S}$ in the $\mathrm{Pdpy}_{2}(\mathrm{SCN})_{2}$. Besides the high frequency of the $\mathrm{C}-\mathrm{N}$ band $\varepsilon_{\max } \Delta \nu_{1 / 2}$ was found to be $0.47 \times 10^{4}\left(\mathrm{M}^{-1} \mathrm{~cm}^{-2}\right)$ compared to $1.53 \times 10^{4}$ for the free thiocyanate ion. The same conclusion was drawn by Sabatini and Bertini ${ }^{4}$ from the $\mathrm{N}-\mathrm{C}-\mathrm{S}$ bending vibration frequency. On the other hand, it seems probable that a change in the electron configuration around the palladium atom takes place so that in Pdpy(NCS) ${ }^{+}$a $\mathrm{Pd}-\mathrm{NCS}$ bond is more stable than a Pd-SCN bond (cf. the low value, $2085 \mathrm{~cm}^{-1}$, for the $\mathrm{C}-\mathrm{N}$ stretching band in this complex). A or $\varepsilon_{\max } \Delta \nu_{1 / 2}$ could not be determined here because the absorption peaks are not sufficiently resolved to allow a measurement of the integrated absorption or the half-width value of this band, but $\varepsilon_{\max }$ is much larger than that of $\operatorname{Pdpy}_{2}(\mathrm{SCN})_{2}\left(c a .1060\right.$ to $\left.372 \mathrm{M}^{-1} \mathrm{~cm}^{-1}\right)$.

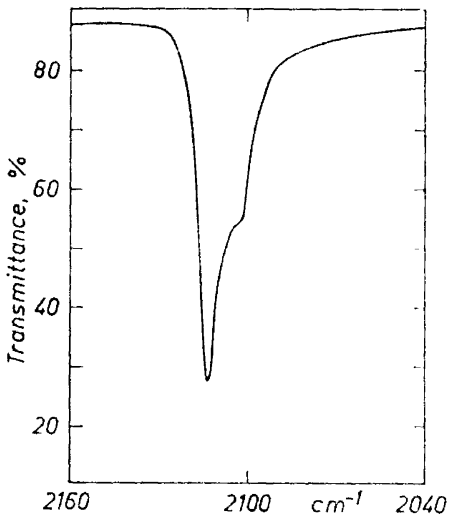

Fig. 3. C-N stretching absorption bands of $\operatorname{Pdpy}_{2}(\mathrm{SCN})_{2}$ in a $\mathrm{KBr}$ disk. The ratio sample $/ \mathrm{KBr}$ is $0.41 \mathrm{mg} / 300 \mathrm{mg}$, the thickness of the disk $0.915 \mathrm{~mm}$ and the volume $0.121 \mathrm{~cm}^{3}$. 
Table 1. Spectral data of the investigated complexes. The values of $\varepsilon_{\max }, \varepsilon_{\max } \Delta v_{1 / 2}$ and $A$ are calculated per SCN group.

\begin{tabular}{|c|c|c|c|c|c|c|}
\hline Compound & $\begin{array}{l}\text { Solvent } \\
\text { etc. }\end{array}$ & $\begin{array}{c}v \\
\left(\mathrm{~cm}^{-1}\right)\end{array}$ & $\left(\begin{array}{c}\varepsilon \\
\left(\mathrm{M}^{-1} \mathrm{~cm}^{-1}\right)\end{array}\right.$ & $\begin{array}{c}\Delta v_{1 / 2} \\
\left(\mathrm{~cm}^{-1}\right)\end{array}$ & $\left|\begin{array}{c}\varepsilon_{\max } \Delta \nu_{1 / 2} \\
\times 10^{-4} \\
\left(\mathbf{M}^{-1} \mathbf{c m}^{-2}\right)\end{array}\right|$ & $\begin{array}{c}A \times 10^{-4} \\
\left(\mathbf{M}^{-1} \mathrm{~cm}^{-2}\right)\end{array}$ \\
\hline NaSCN & $\mathrm{KBr}$ & 2070 & 310 & 39 & 1.22 & 3.25 \\
\hline NaSCN & Pyridine & 2059 & 1020 & 16 & 1.53 & 4.28 \\
\hline $\mathrm{Pdpy}_{2}(\mathrm{SCN})_{2}$ & $"$ & 2116 & 372 & 12.5 & 0.47 & 2.26 \\
\hline $\mathrm{Pdpy}_{3}(\mathrm{NCS})^{+}$ & 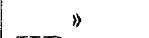 & 2085 & 1060 & - & - & - \\
\hline $\mathrm{Pdpy}_{2}(\mathrm{SCN})_{2}$ & $\mathrm{KBr}$ & 2114,2102 & - & - & - & 1.67 \\
\hline $\mathrm{Pd}\left(\mathrm{P}\left(\mathrm{C}_{6} \mathrm{H}_{5}\right)_{3}\right)_{2}(\mathrm{NCS})_{2}$ & $"$ & 2092 & 720 & 24.5 & 1.76 & 5.76 \\
\hline $\operatorname{Pd}\left(\mathrm{As}\left(\mathrm{C}_{6} \mathrm{H}_{5}\right)_{3}\right)_{2}(\mathrm{NCS})_{2}$ & $"$ & 2088 & 72 & 27 & 1.9 & 6.03 \\
\hline $\operatorname{Pd}\left(\mathrm{As}\left(\mathrm{C}_{8} \mathrm{H}_{5}\right)_{3}\right)_{2}(\mathrm{SCN})_{2}$ & " & 2119 & 350 & 8 & 0.28 & - \\
\hline
\end{tabular}

The spectrum of $\operatorname{Pdpy}_{2}(\mathrm{SCN})_{2}$ in $\mathrm{KBr}$ disks have also been recorded (Fig. 3). A splitting of the $\mathrm{C}-\mathrm{N}$ band is observed with a main peak at $2114 \mathrm{~cm}^{-1}$ and a smaller one rather a shoulder) at $2102 \mathrm{~cm}^{-1}$. A graphical integration of the overall band gave $A=1.67 \times 10^{-4} \mathrm{M}^{-1} \mathrm{~cm}^{-2}$, i.e. well below the corresponding value of NaSCN, $3.25 \times 10^{4} \mathrm{M}^{-1}$ $\mathrm{cm}^{-2}$.

The spectral data of the complexes in this section are included in Table 1.

\section{B. Measurements on $\mathrm{Pd}\left[\mathrm{P}\left(\mathrm{C}_{6} \mathrm{H}_{5}\right)_{3}\right]_{2}(\mathrm{NCS})_{2}$}

Preparation. This complex was prepared just as $\mathrm{Pdpy}_{2}(\mathrm{SCN})_{2}$ above. ${ }^{2} \mathrm{P}\left(\mathrm{C}_{6} \mathrm{H}_{5}\right)_{3}$ was added to the palladium solution dissolved in absolute ethanol.

Results. In this case no convenient solvent could be found in which $\mathrm{Pd}\left[\mathrm{P}\left(\mathrm{C}_{6} \mathrm{H}_{5}\right)_{3}\right]_{2}(\mathrm{NCS})_{2}$ was soluble to any useful degree. The complex was soluble in pyridine but solvolytic reactions resulted in a number of unresolvable absorption peaks, probably corresponding to a set of mixed complexes.

In order to make measurements on the true $\mathrm{Pd}\left[\mathrm{P}\left(\mathrm{C}_{6} \mathrm{H}_{5}\right)_{3}\right]_{2}(\mathrm{NCS})_{2}$ it was necessary to use the $\mathrm{KBr}$ technique. The accuracy decreases, however, essentially due to a nonuniform distribution of the sample in the $\mathrm{KBr}$ disks, but on the other hand the Beer-law plot was still quite good (Fig. 4).

The $\mathrm{C}-\mathrm{N}$ stretching frequency was found to be $2092 \mathrm{~cm}^{-1}$ and $\varepsilon_{\max } \Delta v_{1 / 2}=1.76 \times 10^{4}$ $\mathrm{M}^{-1} \mathrm{~cm}^{-2}$. This value should be compared to $1.22 \times 10^{4} \mathrm{M}^{-1} \mathrm{~cm}^{-2}$ for NaSCN in $\mathrm{KBr}$ disks (Table 1) and indicates $\mathrm{N}$-coordination between the $\mathrm{Pd}^{2+}$ and $\mathrm{SCN}^{-}$ions.

\section{Me asurements on $\operatorname{Pd}\left[\mathrm{As}\left(\mathrm{C}_{6} \mathrm{H}_{5}\right)_{3}\right]_{2}(\mathrm{NCS})_{2}$ and $\operatorname{Pd}\left[\mathrm{As}\left(\mathrm{C}_{6} \mathrm{H}_{5}\right)_{3}\right]_{2}(\mathrm{SCN})_{2}$}

Preparation. Recently Burmeister and Basolo ${ }^{2}$ have made successful measurements on the linkage isomers $\operatorname{Pd}\left[\mathrm{As}\left(\mathrm{C}_{6} \mathrm{H}_{5}\right)_{3}\right](\mathrm{NCS})_{2}$ and $\mathrm{Pd}\left[\mathrm{As}\left(\mathrm{C}_{6} \mathrm{H}_{5}\right)_{3}\right]_{2}(\mathrm{SCN})_{2}$. They prepared them from alcoholic solutions of $\mathrm{K}_{2} \mathrm{Pd}(\mathrm{SCN})_{4}$ and $\mathrm{As}\left(\mathrm{C}_{6} \mathrm{H}_{6}\right)_{3}$ mixed at $0^{\circ} \mathrm{C}$. After the solution had been stirred for a while, they could precipitate the S-bonded product by addition of ice water and isolate it by filtration. The $\mathrm{N}$-bonded isomer that normally is the most stable was then obtained by heating the $\mathrm{S}$-form at $156^{\circ}$ for $30 \mathrm{~min}$. However, we found that $\mathrm{K}_{2} \mathrm{Pd}(\mathrm{SCN})_{4}$ was quite insoluble in absolute ethanol, and thus an aqueous solution had to be used and the temperature kept just above $0^{\circ} \mathrm{C}$. An IR spectrum (of

Acta Chem. Scand. 23 (1969) No. 1 


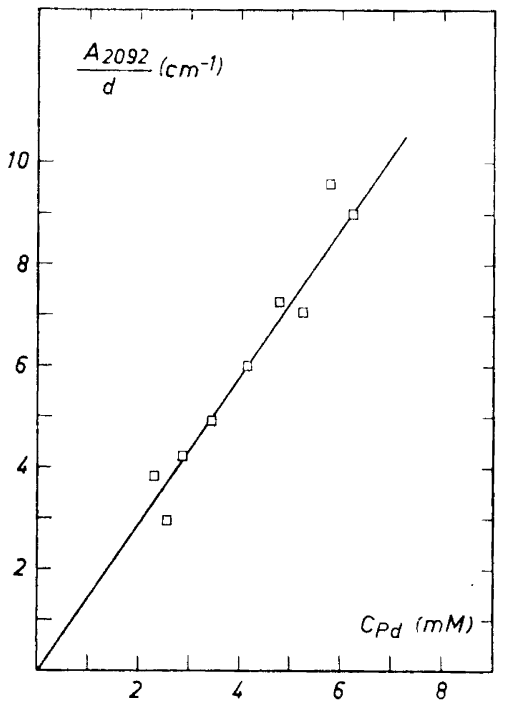

Fig. 4. The Beer-law plot of $\mathrm{Pd}\left[\mathrm{P}\left(\mathrm{C}_{6} \mathrm{H}_{6}\right)_{3}\right]_{2}(\mathrm{NCS})_{2}$.

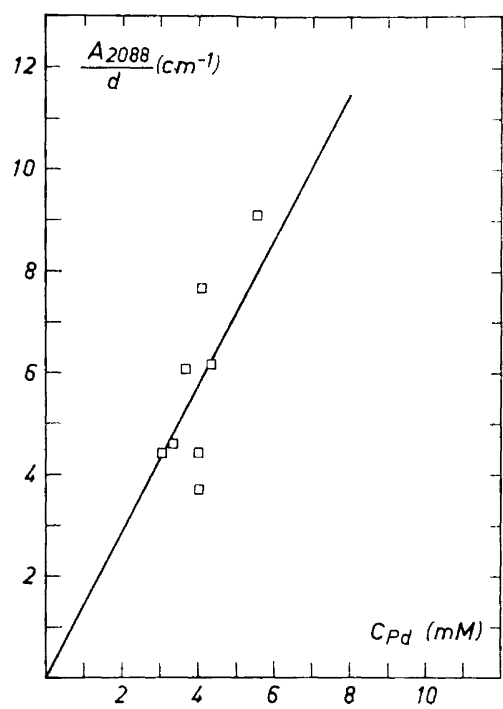

Fig. 5. The Beer-law plot of $\operatorname{Pd}\left[\mathrm{As}\left(\mathrm{C}_{6} \mathrm{H}_{5}\right)_{3}\right]_{2}(\mathrm{NCS})_{2}$.

a $\mathrm{KBr}$ disk) of the preparate so produced gave two absorption peaks in the $\mathrm{C}-\mathrm{N}$ frequency range (2119 and $2088 \mathrm{~cm}^{-1}$, respectively) corresponding to one $\mathrm{S}-$ and one $\mathrm{N}$ bonded isomer, but we cannot tell if we got this composition of the sample as a result of working at too high a temperature during the preparation. Indeed, it seems probable that a pure $\mathrm{S}$-form would partly isomerize to $\mathrm{N}$-form when exposed to the high pressure and high temperature that are generated by the pressing of the $\mathrm{KBr}$ disks. If the preparate at first was heated to c. $130^{\circ}$ for some hours only one peak was observed in the IR spectrum, situated at $2088 \mathrm{~cm}^{-1}$ and corresponding to the $\mathrm{C}-\mathrm{N}$ vibration of a pure $\mathrm{N}$-form.

Results. As it was possible to prepare the pure $\mathrm{N}$-form by heating the S-form $\varepsilon_{\max }$ and $\varepsilon_{\max } \Delta \nu_{1 / 2}$ for $\operatorname{Pd}\left[\mathrm{As}\left(\mathrm{C}_{6} \mathrm{H}_{5}\right)_{3}(\mathrm{NCS})_{2}\right.$ could be determined. Knowing $\varepsilon_{\max } \mathrm{N}$ and the total concentration, $\varepsilon_{\max }$ and $\varepsilon_{\max } \Delta v_{1 / 2}$ for the $\mathrm{S}$-form could also be calculated. However, as mentioned above, the $\mathrm{KBr}$ procedure is scarcely perfect for quantitative measurements. The Christiansen-effect ${ }^{21}$ is one contributory factor to the observation that measurements on an absorption peak of a solid sample tend to give only approximate values.

The following results were obtained:

$$
\begin{array}{ll}
\varepsilon_{\max }{ }^{\mathrm{N}}=720 \pm 100 & \left(\mathrm{M}^{-1} \mathrm{~cm}^{-1}\right) \\
\varepsilon_{\max }{ }^{\mathrm{N}} \Delta v_{1 / 2}=(1.94 \pm 0.30) \times 10^{4} & \left(\mathrm{M}^{-1} \mathrm{~cm}^{-2}\right) \\
\varepsilon_{\max } \mathrm{S}=350 \pm 200 & \left(\mathrm{M}^{-1} \mathrm{~cm}^{-1}\right) \\
\varepsilon_{\max } \mathrm{S} \Delta \nu_{1 / 2}=(0.28 \pm 0.15) \times 10^{4} & \left(\mathrm{M}^{-1} \mathrm{~cm}^{-2}\right)
\end{array}
$$

It can be seen that the values for the S-form are very uncertain, but nevertheless we can demonstrate that $\varepsilon_{\max } \mathrm{s} \Delta \nu_{1 / 2}$ are lower and $\varepsilon_{\max }{ }^{\mathrm{N}} \Delta v_{1 / 2}$ higher than the same quantity of NaSCN, $1.22 \times 10^{4}\left(\mathrm{M}^{-1} \mathrm{~cm}^{-2}\right)$. The results are included in Table 1. Fig. 5 shows the Beer-law plot of the N-bonded isomer. 
Of course it would be desirable to get more exact values of $\varepsilon_{\max }$ and $\varepsilon_{\max } \Delta \nu_{1 / 2}$ than the $\mathrm{KBr}$ method will permit. The compound is little soluble in, e.g., alcohol, benzene, and chloroform, but still if a good solvent is to be found one cannot get a solution of pure $\mathrm{S}$ - or $\mathrm{N}$-form, because in solution there is a rapid isomerization giving a mixture of the two forms. In Nujol mulls perhaps one could get the pure forms but it is a bad tool for intensity measurements.

\section{CONCLUSIONS}

Pecile ${ }^{7}$ has also made measurements on the integrated absorption of the $\mathrm{C}-\mathrm{N}$ band, although on other thiocyanato complexes and only on solutions. He has calculated the integrated absorption with Ramsay's method of direct integration ${ }^{20}$ and found the S-bonded complexes to have $A$ between $0.8-2.3 \times 10^{4}$ and the N-bonded ones between $9-12 \times 10^{4}\left(\mathrm{M}^{-1} \mathrm{~cm}^{-2}\right)$. The corresponding ranges of $\varepsilon_{\max } \Delta \nu_{1 / 2}$ as calculated from the reported values of $\varepsilon_{\max }$ and $\Delta \nu_{1 / 2}$ would be $0.24-0.60 \times 10^{4}$ and $1.83-4.20 \times 10^{4} \mathrm{M}^{-1} \mathrm{~cm}^{-2}$. However, the integrated absorption of a compound is dependent of the solvent used, as is very well illustrated by Pecile's values of A for KSCN in various solvents. The same behaviour is found when going from solutions to $\mathrm{KBr}$ disks ( $c f$. Table 1). For this reason it is difficult to make any accurate comparison between results obtained in different solvents and by different sampling techniques. But it seems always to be true that the integrated absorption (or $\varepsilon_{\max } \Delta \nu_{1 / 2}$ ) for the $\mathrm{N}$-bonded complexes are larger and the $\mathrm{S}$-bonded ones smaller than the same quantity of the "free" thiocyanate ion (NaSCN or KSCN) when using the same solvent or dispersion medium and the same technique.

The financial support of the Swedish Natural Science Research Council and the Faculty of Science, Lund, is gratefully acknowledged.

\section{REFERENCES}

1. Fronæus, S. and Larsson, R. Acta Chem. Scand. 16 (1962) 1447.

2. Burmeister, J. L. and Basolo, F. Inorg. Chem. 3 (1964) 1587.

3. Sabatini, A. and Bertini, I. Inorg. Chem. 4 (1965) 959.

4. Sabatini, A. and Bertini, I. Inorg. Chem. 4 (1965) 1665.

5. Bertini, I. and Sabatini, A. Inorg. Chem. 5 (1966) 1025.

6. Clark, R. J. H. and Williams, C. S. Spectrochim. Acta 22 (1966) 1081.

7. Pecile, C. Inorg. Chem. 5 (1966) 210.

8. Bennett, M. A., Clark, R. J. H. and Goodwin, A. D. J. Inorg. Chem. 6 (1967) 1625.

9. Larsson, R. and Miezis, A. Acta Chem. Scand. 19 (1965) 47.

10. Cotton, F. A., Goodgame, D. M. L., Goodgame, M. and Sacco, A. J. Am. Chem. Soc. 83 (1961) 4157.

11. Jones, L. H. J. Chem. Phys. 25 (1956) 1069.

12. Kharitonov, Yu. Ya., Tsintsadze, G. V. and Porai-Koshits, M. A. Russ. J. Inorg. Chem. 10 (1965) 427.

13. Fronæus, S. and Larsson, R. Acta Chem. Scand. 16 (1962) 1433.

14. Nakamoto, K. Infrared Spectra of Inorganic and Coordination Compounds, Wiley, New York 1963.

15. Nancollas, G. H., Park, A. and Torrance, K. Proc. 9th Intern. Conf. Coordination Chem. St. Moritz-Bad 1966, p. 86.

16. Tramer, A. J. Chim. Phys. 59 (1962) 232.

Acta Chem. Scand. 23 (1969) No. 1 
17. Figgis, B. N. Introduction to Ligand Fields, Wiley, New York 1966.

18. Oba, K., Watari, F. and Aida, K. Spectrochim. Acta A 23 (1967) 1515.

19. Larsson, R. and Miezis, A. Acta Chem. Scand. 22 (1968) 3261.

20. Ramsay, D. A. J. Am. Chem. Soc. 74 (1952) 72.

21. Jones, R. N. and Sandorfy, C. The application of infrared and raman spectroscopy to the elucidation of molecular structure, Chapter IV, In Weissberger, A., (Ed.), Technique of Organic Chemistry, Volume IX. Interscience, New York 1956.

Received May 22, 1968. 